Proc. of the 11 Int. School on Theoretical Physics Symmetry and Structural Properties of Condensed Matter, Rzeszów 2014

\title{
Supercapacity of Soft-Expanded Graphite in Li-Intercalational Electric Current Generation
}

\author{
R.Ya. Shvets ${ }^{a}$, I.I. Grygorchak ${ }^{a}$, A.S. Kurepa ${ }^{a}$, N.T. Pokladok ${ }^{a}$, Yu.I. Sementsov ${ }^{b}$, \\ G.I. DovbeshKo ${ }^{c}$, Ye. Sheregit ${ }^{d}$ AND B. SEREDYUK ${ }^{e, *}$ \\ ${ }^{a}$ Lviv Polytechnic National University, Bandera Str. 12, Lviv, 79013, Ukraine \\ ${ }^{b}$ Chuiko Surface Institute of Chemistry, National Academy of Sciences of Ukraine, \\ General Naumov str. 17, Kyiv, 03164, Ukraine \\ ${ }^{c}$ Institute of Physics of NAS of Ukraine, Prospect Nauky, 46, Kyiv, 03028, Ukraine \\ ${ }^{d}$ University of Rzeszów, Centre for Microelectronics and Nanotechnology, S. Pigonia 1, 35-959 Rzeszów, Poland \\ ${ }^{e}$ Academy of Land Forces named after Hetman Petro Sahajdachnyj, Faculty of Rocket Troops and Artillery, \\ Geroiv Majdanu str. 32, Lviv 79012, Ukraine
}

\begin{abstract}
A microwave-intercalation modification of natural graphite which ensures its effective use as a cathode material of Li-based sources of electric current is developed. Interconnection between the parameters of modification and thermodynamic and kinetic behavior of Li-intercalation electric current generation is established. On the basis of the obtained data from impedance spectroscopy, X-ray diffractometry analysis, and spectroscopy of the Raman scattering of light, the mechanism of the observed phenomena is suggested.
\end{abstract}

DOI: 10.12693/APhysPolA.128.208

PACS: $81.16 . \mathrm{Fg}, 82.45 . \mathrm{Vp}$

\section{Introduction}

In recent works [1, 2], a very interesting and promising approach is suggested in materials science for autonomous power engineering devices; in accordance with this approach, a highly effective material for capacitive accumulation of energy in super capacitors is obtained through exposing oxidized graphite to microwave electromagnetic radiation followed by the introduction of porosity by means of KOH-modification. Such material enables us to achieve a specific area of the active surface of a modified structure about $3.1 \mathrm{~m}^{2} / \mathrm{g}$ and excellent operational qualities.

A microwave treatment of the graphite previously intercalated by the sulphuric acid was carried out. Graphite was used with the size of its particles of $300 \mu \mathrm{m}$. The process of the treatment of hydrolyzed intercalation graphite (HIG) of the 1st stage of ordering was carried out in a field of microwave radiation whose frequency was $2458 \mathrm{MHz}$. The intervals of radiation duration were 10, 20, 40, and $60 \mathrm{~s}$.

From the point of view of unification of the devise making processes for autonomous power engineering, the possibility of application of such multilayered graphene-bind structures for Li-intercalation current generation is of interest without a doubt. At the same time, this can be a valuable substratum for solving one of the most important nowadays problems in the branch of electrochemical power engineering - formation of a new resources

* corresponding author; e-mail: b.seredyuk@gmail.com basis consisting of inexpensive, ecologically safe and widely spread in nature substances.

It is evident that for this purpose a more detailed study of atomic structure as well as rich knowledge in thermodynamics and kinetics of intercalation processes into these multilayered graphene-bind structures, are unfortunately, lacking. This work is dedicated to address the above mentioned issues.

\section{Results and discussion}

Figure 1 shows X-ray diffractograms of HIG before and after radiation which causes the expansion of its matrix. Oscillations seen in Fig. 1 are considered as an

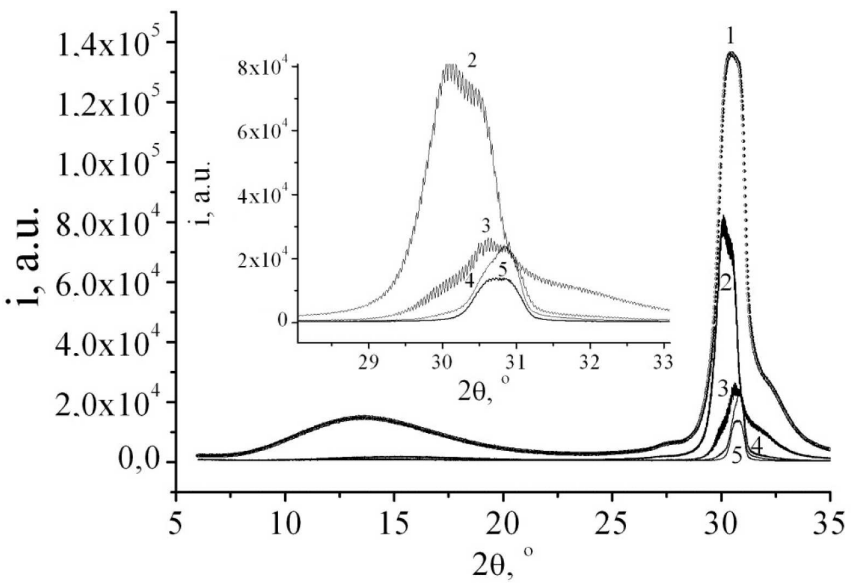

Fig. 1. X-ray diffractograms of HIG before (curve 1) and after expansion in microwave electric field for 10 (curve 2), 20 (curve 3), 40 (curve 4), and 60 (curve 5) s. In the inset - thin structure of diffraction maxima. 
evidence of perfection of graphene structures the thickness of which can be estimated on the basis of the period of such oscillations [3].

The Nyquist diagrams for HIG are shown in Fig. 2. In the inset on top of Fig. 2 there is depicted the equivalent electric scheme for modelling of the experimental data outlined on the graph. The mid frequency branches of curves 4 and 5 are linear for these values of guest load $x$. That cannot be explained by spherical diffusion because platelet shape form of the initial graphite did not change after the irradiation but may be associated with the transformation of elementary volumes of parts of graphene packs.

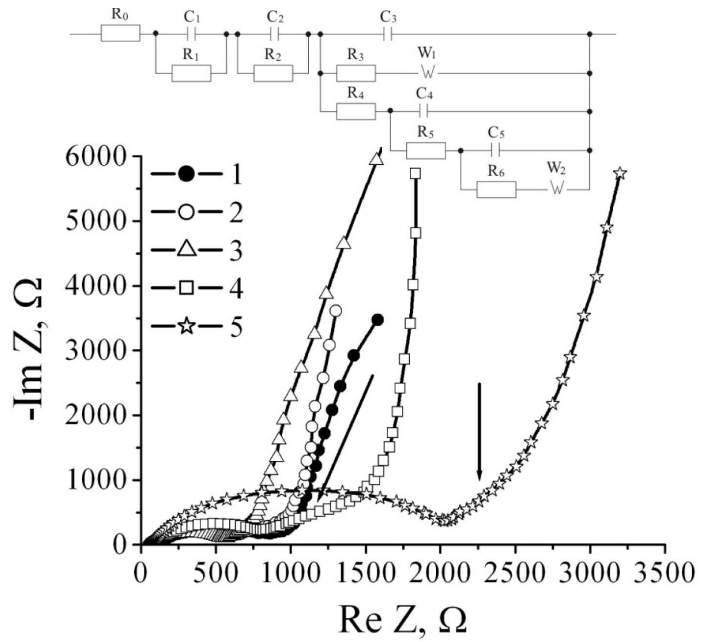

Fig. 2. Nyquist diagrams for HIG before (curve 1) and after microwave irradiation for 10 (curve 2), 20 (curve 3), 40 (curve 4), and 60 (curve 5) s for initial stages $(x \approx 0)$.

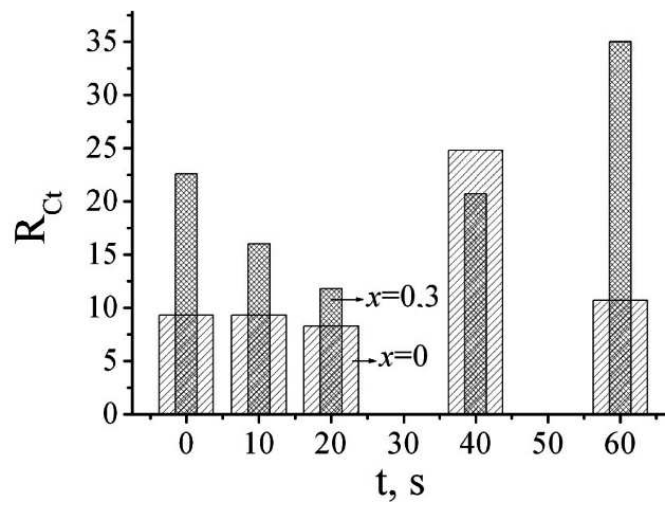

Fig. 3. A dependence of the resistance of current transition from electrolyte into oxidized graphite on various regimes of microwave irradiation taken for two values of guest load $x=0$ and $x=0.3$.
A dependence of the current transition resistance on the duration of irradiation is shown in Fig. 3. Here a different behavior of $R_{c t}$ for 40 and $60 \mathrm{~s}$ regimes may be caused by the increase in the density of states at the Fermi level at the expense of greater extent of the reduction of the system disordering under the given regimes.

\section{Conclusions}

The possibility of application of HIG intercalated by the sulphuric acid and subsequently treated by the microwave electromagnetic radiation for high electric power generation according to the lithium-intercalation mechanism of current-generation reaction has been proved.

The studied structure of HIG was shown to have a large value of specific capacity ranging up to $Q=2250 \mathrm{mAh} / \mathrm{g}$ for a 60 -second irradiation regime. The duration of the HIG irradiation of up to a 60-second exposure time at the given power of electromagnetic radiation of $700 \mathrm{~W}$ is sufficient for the needed increase of the distance between the graphene layers, i.e. for the formation of graphenebind structures.

A diffusion coefficient for highly expanded intergraphene domains has the maximum value for a $60 \mathrm{~s}$ irradiation regime. At the same time, for this regime, the coefficient of diffusion in less expanded domains is lower than the one of the unexpanded matrix.

\section{References}

[1] Y.W. Zhu, S. Murali, M.D. Stoller, A. Velamakanni, R.D. Piner, R.S. Ruoff, Carbon 48, 2118 (2010).

[2] Y. Zhu, S. Murali, M.D. Stoller, K.J. Ganesh, W. Cai, P.J. Ferreira, A. Pirkle, R.M. Wallace, K.A. Cychocz, M. Thommes, D. Su, E.A. Stach, R.S. Ruoff, Science 332, 1537 (2011).

[3] M.A. Chuev, E.M. Pashaev, M.V. Koval'chuk, V.V. Kvardakov, J. Exp. Theor. Phys. Lett. 90, 186 (2009). 